\title{
SWARA Temelli Bulanık COPRAS Yöntemi ile Soğuk Hava Deposu Seçimi
}

\author{
Ali KATRANCI*, Nilsen KUNDAKCI**
}

\section{ÖZ}

Bireylerin dengeli ve sağlıklı bir şekilde beslenmeleri açısından son derece önemli olan meyve ve sebzelerin hasat dönemi dışında da tüketilebilmesi için iyi bir şekilde muhafaza edilmeleri gerekmektedir. Meyve ve sebzelerin, hasattan sonra yapılarında meydana gelebilecek bozulmaları engelleyerek, tüm yıl boyunca ilk günkü tazeliğini koruması açısından soğuk hava depoları oldukça önemli bir rol oynamaktadır. Bu çalışmada, Denizli ilinin Çivril ilçesinde bulunan, her türlü meyve ve sebzenin depolanabildiği soğuk hava depo alternatifleri Çok Kriterli Karar Verme (ÇKKV) yöntemlerinden SWARA ve Bulanık COPRAS yöntemleri ile değerlendirilmiştir. SWARA yöntemi ile kriterlerin ağırlıkları belirlenerek, Bulanık COPRAS yöntemi ile alternatifler sıralanmıştır. Çalışmanın sonunda çiftçiler için en uygun soğuk hava deposu belirlenmiştir.

Anahtar Kelimeler: ÇKKV, SWARA, Bulanık COPRAS, Soğuk hava deposu seçimi

JEL Sinıflandırması: C02, C44, D81

\section{Selection of Cold Storage by SWARA Based Fuzzy COPRAS Method}

\begin{abstract}
Fruits and vegetables, which are extremely important for people to be nourished in a balanced and healthy manner need to be stored in a good way in order to be consumed even outside their harvesting periods. Cold storage depots play a significant role in terms of preserving their initial freshness throughout the year by preventing the deterioration of the fruits and vegetables after the harvest. In this study, different cold storage depot alternatives for all kind of fruits and vegetables, located in Çivril district in the city of Denizli, have been evaluated by using two MutiCriteria Decision Making (MCDM) methods which are SWARA and fuzzy COPRAS methods. After the weights of the criteria have been determined with SWARA method, the alternatives have been ranked using the fuzzy COPRAS method. At the end of the study, the most suitable cold storage has been determined for the farmers.
\end{abstract}

Keywords: MCDM, SWARA, Fuzzy COPRAS, Cold storage selection

JEL Classification: C02, C44, D81

Geliş Tarihi / Received: 12.02.2019 Kabul Tarihi / Accepted: 21.07.2019

* Doktora Öğrencisi, Pamukkale Üniversitesi, Sosyal Bilimler Enstitüsü, akatrancii@gmail.com, ORCID: 0000-00027586-1169.

** Doç. Dr., Pamukkale Üniversitesi, İ̈BF, İşletme Bölümü, nilsenk@pau.edu.tr, ORCID: 0000-0002-7283-320X. 


\section{GİRIŞ}

Ülkemiz, dünya üzerindeki konumu nedeniyle meyve ve sebze yetiştiriciliği yönünden oldukça uygun bir iklime sahiptir. Bu nedenle hemen hemen tüm bölgelerimizde meyve ve sebze yetiştiriciliği belirli dönemlerde yapılmakta ve bu ürünlere tüm y1l boyunca ihtiyaç duyulmaktadır (Gençoğlan vd., 2016: 67).

Tüm yıl meyve ve sebzelere ulaşmak, yıpranmalarını engellemek, hasattan sonra yapılarında oluşacak biyokimyasal etkileşimleri mümkün olan en düşük düzeye indirmek amacıyla donma noktalarının biraz üzerindeki 1s1 derecelerinde saklanmaları gerekmektedir (Timur, 1985: 56). Soğuk depolama ya da soğuk muhafaza olarak adlandırılan bu yöntemin tarihi doğal mağaralarda başlamaktadır. Romalılar M.Ö. 100. yılın ilk yarısında ilk depolama bilgileri ile ilk mimarları olmuşlardır (Nizamoğlu ve Gökmen, 2017: 43). Aynı zamanda soğuk depolama için oda kurma uğraşını ise ilk olarak İmparator Neron vermiştir. Gıdaları güneş etkisinden korumak için samanla izole edilmiş odalar yaptırmıştır (Çullu, 2017: 48).

Günümüzde depolama faaliyetlerinde, bilim ve teknolojide yaşanan gelişmeler sayesinde hızlı bir gelişme gözlenmiştir. Sebze ve meyvelerin soğuk hava depolarında, modern ve uzun süre muhafaza imkânı tanıyan makineler yardımıyla, bozulma ve çürümeleri önlenebilmektedir. Ayrıca, depolanan ürünün ticari getirisi artmakta, ürünler daha uzun süre depolanabilmekte, kalite kayıları azalmakta, her mevsim uygun fiyata taze meyve ve sebze bulmak mümkün hale gelmekte ve bu faaliyetler paketlemeden nakliyeye kadar birçok sektörde istihdam sağlamaktadır (Sargin ve Okudum, 2014: 112).

$\mathrm{Bu}$ çalışmada, Denizli ilinin Çivril ilçesinde yer alan ve ürünlerin çabuk bozulmasını engelleyerek, ilk günkü tazeliği ile her mevsim tüketilmesini sağlayan soğuk hava deposu seçim problemi ele alınmıştır. Çalışmada, kriter ağıllıklarının belirlenmesinde SWARA yöntemi kullanılmıştır. Kriter ağırlıklarını belirlemek için literatürde AHP, MACBETH, Entropi gibi farklı yöntemler de kullanılabilmektedir. Bu çalışmada SWARA yönteminin seçilmesinin nedeni yöntemin diğer yöntemlere göre hesaplama kolaylığı sunması ve daha yeni bir yöntem olmasıdır. Ayrıca SWARA yöntemi, karar vericilere kendi önceliklerini belirlemelerine izin vermekte ve bunu yaparken AHP ve MACBETH yöntemlerinde olduğu gibi karmaşık ikili kıyaslamalara gerek duymamakta böylece tutarsızlık durumuyla da karşı karşıya kalınmamaktadır. Soğuk hava deposu alternatiflerinin değerlendirilmesinde ise, literatürde az sayıda çalışma yapılmış olan bulanık COPRAS yöntemi kullanılmıştır. Karar vericilerin, alternatifleri kesin ifadelerle değerlendirilmesinde zorluk yaşaması ve ele alınan karar probleminin belirsizlik içermesi nedeniyle Bulanık ÇKKV yöntemlerinden biri tercih edilmiştir. Karar vericiler tarafından alternatifler değerlendirilirken sözel değişkenler kullanılarak en uygun soğuk hava deposu belirlenmiştir. Ayrıca, alternatiflerin değerlendirilmesinde Bulanık TOPSIS, Bulanık ELECTRE, Bulanık MOORA gibi farklı bulanık ÇKKV yöntemleri de kullanılabilir. Bu çalışmada, Bulanık COPRAS yönteminin seçilmesinin nedeni, bu alanda yapılan çalışma sayısının az olması ve yöntemin kriter ve alternatif sayısı fazla olsa bile karmaşık hesaplamalar içermemesidir. Bulanık COPRAS yönteminin diğer önemli bir özelliği de, hesaplanan performans indeksi sayesinde alternatiflerin almış oldukları değerler yüzde olarak ifade edilebilmekte, bu da alternatifler arasında karşılaştırma yapmayı kolaylaştırmaktadır. Bu çalışmanın özgün yanı, SWARA ve bulanık COPRAS yöntemlerinin bir arada kullanılması ve bu yöntemlerin soğuk hava deposu seçimi gibi farklı bir alana uygulanmasıdır. Bu iki açıdan, literatüre katkı sağlanmaktadır. Bunların yanında, çiftçilere meyve sebzelerinin bozulmasını engelleyerek her mevsim tüketilmelerini sağlayan en uygun soğuk hava deposunun seçiminde yol gösterilmiştir.

Çalışmanın ikinci bölümünde kriter ağırlıklarının belirlenmesinde kullanılan SWARA yöntemi açıklanmıştır. Üçüncü bölümde, bulanık küme kavramı tanımlanarak, bulanık sayılar ve sözel değişkenler açıklanmıştır. Dördüncü bölümde bulanık COPRAS yöntemine değinilmiş ve yöntemin adımları özetlenmiştir. Beşinci bölümde, SWARA ve bulanık COPRAS yöntemleri ile 
en iyi soğuk hava deposu seçimi yapılmıştır. Altıncı bölümde, çalıma sonucu elde edilen bulgulara yer verilerek gelecek çalışmalar için önerilerde bulunulmuştur.

\section{SWARA YÖNTEMI}

SWARA (Step-Wise Weight Assessment Ratio Analysis) yöntemi, Keršuliene, Zavadskas ve Turskis (2010) tarafindan geliştirilmiştir ve özellikle kriterlerin ağırlıklandırılmasında yaygın olarak kullanılmaktadır. SWARA yöntemi, mevcut çevresel ve ekonomik durumları dikkate alarak, karar vericilere kendi önceliklerini belirlemelerine izin vermekte, böylece bu yöntemde karar vericiler önemli bir role sahip olmaktadır (Çakır ve Akar, 2017: 208).

SWARA yönteminin çeşitli alanlarda uygulamaları mevcuttur. $\mathrm{Bu}$ çalışmalara, uyuşmazlık çözümü (Keršuliene, Zavadskas ve Turskis, 2010), enerji sistemlerinin sürdürülebilirliği için yatırım alternatiflerinin değerlendirilmesi (Zolfani ve Saparauskans, 2013), ürün tasarımı (Zolfani vd., 2013a), yer seçimi (Zolfani vd., 2013b), ısı yalıtımı seçimi (Ruzgys vd., 2014), yatırım seçimi (Zolfani ve Bahrami, 2014), personel seçimi (Dahooie vd., 2018; Karabašević vd., 2015; Karabašević vd., 2016a; Stanujkic vd., 2015a; Urosevic vd. 2017; Zolfani ve Banihashemi, 2014), 1şık kaynağı seçimi (Nakhaei vd., 2016), ambalaj tasarımı (Stanujkic vd., 2015b), otel seçimi (Tuş Işık ve Adalı, 2016), malzeme seçimi (Yazdani vd., 2016), ERP yazılımı seçimi (Shukla vd., 2016), işletmelerin kurumsal sosyal sorumluluklarına göre değerlendirilmesi (Karabašević vd., 2016b), makine seçimi (Çakır ve Akar, 2017), sunucu seçimi (Yurdoğlu ve Kundakcı, 2017), risk değerlendirme (Valipour vd., 2017), müteahhit firma seçimi (Çakır, 2017), tedarikçi seçimi (Adalı ve Tuş Işık, 2017; Toklu vd., 2018) ve performans değerlendirme (Özbek ve Demirkol, 2018) örnek verilebilir. Bu çalışmalarda SWARA yöntemi genellikle kriter ağırlıklarının belirlenmesinde kullanılarak diğer Çok Kriterli Karar Verme (ÇKKV) yöntemleri ile bir arada kullanılmıştır.

SWARA yönteminin çözüm adımları aşağıdaki gibidir (Keršuliene, Zavadskas ve Turskis 2010: 250; Yurdoğlu ve Kundakc1, 2017: 258):

Adım 1: Karar vericiler kendisine göre en önemli kritere 1,00 puanını atar. Geriye kalan kriterlere ise en önemli kriter değeri dikkate alınarak 0 ile 1 arasında beşin katları olacak şekilde puan atamas1 yapilır.

Adım 2: $j$ kriterleri, $k$ da karar vericileri göstermek üzere kriterlere atanan puanlar $p_{j}{ }^{k}$ ile ifade edilir. Daha sonra, karar vericilerin kriterlere atadıkları göreli önem puanlarının ortalaması $\overline{p_{j}}$ Eşitlik (1) yardımıyla hesaplanır.

$$
\bar{p}_{j}=\frac{\sum_{k=1}^{K} p_{j}^{k}}{K} ; j=1, \ldots n
$$

Adım 3: Eşitlik (1) ile hesaplanan tüm kriterlerin göreli ortalama önem puanları büyükten küçüğe doğu sıralanır ve karşılaştırılır. Daha sonra $s_{j}$ olarak gösterilen ortalama değerin karşılaştırmalı önemi hesaplanır. $c_{j}$ değerleri, kriter $j+1$ 'in $j$ kriterine göre ne kadar daha önemli olduğunu gösterir.

Adım 4: $c_{j}$ tüm kriterlerin katsayı değerini göstermek üzere, Eşitlik (2) yardımıyla hesaplanır. En büyük $s_{j}$ değerine sahip kriterin katsayısı $c_{j}=1$ değerini göstermektedir. 
$c_{j}=s_{j}+1 ; j=1, \ldots, n$

Adım 5: $s_{j}^{\prime}$ tüm kriterler için düzeltilmiş ağırlık değerini göstermek üzere Eşitlik (3) yardımıyla hesaplanır. İlk sırada yer alan kriter $s_{j}^{\prime}=1$ olmaktadır.

$$
s_{j}^{\prime}=\frac{s_{j-1}^{\prime}}{c_{j}}
$$

Adım 6: $w_{j}$ tüm kriterlerin nihai ağırlık değerlerini göstermek üzere Eşitlik (4) yardımıyla hesaplanir.

$$
w_{j}=\frac{s_{j}^{\prime}}{\sum_{j=1}^{n} s_{j}^{\prime}} ; \quad j=1, \ldots, n
$$

\section{BULANIK KÜME}

Bulanık küme kavramı ilk kez Lotfi A. Zadeh (1965) tarafindan ortaya atılmıştır. Zadeh, niteliklerin ikili üyelik fonksiyonuyla ifade edildiği klasik kümelerin yerine dereceli üyelik fonksiyonu ile ifade edildiği bulanık kümeleri önermiştir (Baykal ve Beyan, 2004: 74). Klasik küme teorisinde, bir eleman kümenin elamanıdır ya da elemanı değildir ve eleman olma ile olmama arasında kesin bir ayrım mevcuttur. Fakat gerçek hayattaki birçok durum klasik küme teorisi ile açıklanamaz (Chen ve Pham, 2001:1). Bulanık küme, klasik kümenin genişletilmiş şeklidir ve bulanık kümeler kısmi üyeliğe olanak tanır. Zadeh, bulanık küme elemanlarının üyelik derecelerini göstermek için 0 ile 1 arasında değişen değerlerin kullanılmasını önermiştir. "0" üye olmamayı gösterirken, "1" tam üyeliği ifade eder. Ara üyelik değerleri ise 0 ile 1 arasında değişen değerler ile gösterilir. Bir başka tanıma göre; bulanık küme, devamlı üyelik derecesine sahip nesneler kümesidir ve her nesneyi 0 ile 1 arasında değişen üyelik derecesine sahip üyelik fonksiyonu ile nitelendirmektedir (Baykal ve Beyan, 2004: 74).

\subsection{Bulanık Sayılar}

Bulanık sayılar dışbükey, normalleştirilmiş, sınırl1-sürekli üyelik fonksiyonu olan ve gerçel sayılarda tanımlanmış bulanık küme olarak tanımlanır. Bulanık sayı normal ve dışbükeydir, normallik, en yüksek üyelik değerinin 1 olmasını ifade eder. (Baykal ve Beyan, 2004: 223) Ele alınan konuya göre farklı bulanık sayılar tanımlanmıştır. Genellikle uygulamalarda üçgen ve yamuk bulanık sayılar kullanılmaktadır. Bu çalışmada üçgen bulanık sayılar kullanıldığı için üçgen bulanık sayılar tanımlanmıştır.

Üçgen bulanık sayılar, bulanık sayıların özel bir çeşididir ve $\tilde{A}=(l, m, u)$ şeklinde ifade edilir. $l, m$, ve $u$ parametreleri, sırasıyla en küçük olası değeri, en olası değeri ve en büyük olası değeri gösteren gerçek sayılardır. Üçgen bulanık sayı $\tilde{A}$ 'nın gösterilişi Şekil 1'de görülmektedir (Kahraman vd., 2004: 174). 


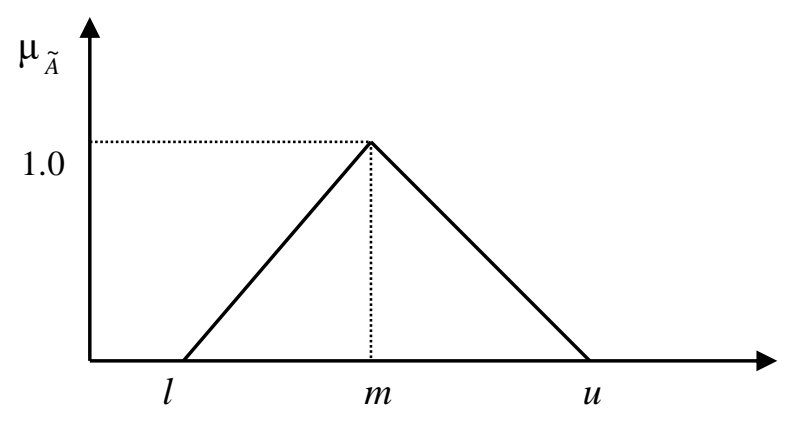

Şekil 1. Üçgen bulanık sayı $\tilde{A}$

Üçgen bulanık sayı $\tilde{A}$ 'nın üyelik fonksiyonu Eşitlik (5)'te görüldüğü gibi ifade edilir:

$$
\mu(x / \tilde{A})= \begin{cases}0, & x<l, \\ (x-l) /(m-l), & l \leq x \leq m, \\ (u-x) /(u-m), & m \leq x \leq u, \\ 0, & x>u\end{cases}
$$

\subsection{Sözel Değişkenler}

Sözel değişken, değişken değeri olarak bir dildeki kelimeleri alabilen değişkene denir (Zadeh, 1975:199). Bahsi geçen kelimeler, klasik küme teorisinde sınır koşulunun net olarak ifade edilemediği kelimelerdir. Bazı kelimelerin anlamı, karmaşıklık ya da belirsizlik gösterdiği için sözel değişkenin bulanık kümelere dayanarak tanımlanması gerekebilir. Sözel değişkenler, net olarak ifade edilemeyen kavramların yaklaşık olarak nitelenmesine yardımcı olur (Özkan, 2003: 126).

\section{BULANIK COPRAS YÖNTEMI}

1996 yılında Zavadskas ve Kaklauskas tarafından geliştirilen COPRAS (COmplex PRoportional ASsesment) yöntemi, alternatifleri önem ve fayda değerlerine göre değerlendirme ve sıralama mantığına dayanmaktadır. Yöntemin hedefi, alternatiflerin değerlendirilmesinde kullanılan kriter değerlerinden fayda değerlerinin en üst düzeye çıkarılması ve faydasız değerlerin ise en aza indirilmesidir (Karaatlı vd., 2015: 180).

COPRAS yönteminde, alternatif ve kriter değerlerinin, net değerler olarak ele alınması gerçek dünyada karar almak için belirsiz ve yetersizdir. Bu belirsizlik ve yetersizliği ortadan kaldırmak amacıyla bulanık COPRAS yöntemi geliştirilmiştir (Nguyen vd., 2015: 5). Bulanık COPRAS yöntemi ile çeşitli alanlarda yapılmış çalışmalar mevcuttur. Bu çalışmalara, kırsal binaların yenilenmesi alternatiflerinin değerlendirilmesi (Zavadskas ve Antucheviciene, 2007), risk analizi (Yazdani vd., 2011), çalışma stratejilerinin değerlendirilmesi (Fouladgar vd., 2012), rüzgar çiftliği için yer seçimi (Chatterjee ve Bose, 2013a), takım tezgahı değerlendirme (Nguyen vd., 2015), altı sigma proje seçimi (Çakır ve Özdemir, 2016), tedarikçi seçimi (Khorasani, 2018; Nourianfar ve Mortazer, 2013; Zarbakhshnia vd., 2018), performans değerlendirme (Ebrahimi, 2016; Turanoğlu Bekar vd. 2016), kentsel ulaşım sistemi için stratejik planlama (Hatefi, 2018) ve satıcı seçimi (Chatterjee ve Bose, 2013b) örnek olarak verilebilir.

Bulanık COPRAS yönteminin çözüm adımları aşağıdaki gibidir (Yazdani vd., 2011: 30): 
Adım 1: Öncelikle karar vericiler tarafından kriterler ve alternatifler belirlenir. Daha sonra bu belirlenen kriterler ve alternatifler Tablo 1 ve Tablo 2'de yer alan sözel değişkenlerden yararlanarak karar vericiler tarafindan değerlendirilir.

\section{Tablo 1: Kriterler için Sözel Değiş kenler}

\begin{tabular}{lc}
\hline Sözel Değişkenler & Bulanık Sayılar \\
\hline Çok Düşük (ÇD) & $(0,0,0.25)$ \\
Düşük (D) & $(0,0.25,0.50)$ \\
Orta (O) & $(0.25,0.50,0.75)$ \\
Yüksek (Y) & $(0.50,0.75,1.0)$ \\
Çok Yüksek (ÇY) & $(0.75,1.0,1.0)$ \\
\hline
\end{tabular}

Kaynak: (Yazdani, 2011: 30; Chang vd., 2012: 7395)

Tablo 2: Alternatifler için Sözel Değişkenler

\begin{tabular}{lc}
\hline \multicolumn{1}{c}{ Sözel Değişkenler } & Bulanık Sayılar \\
\hline Çok Düşük (ÇD) & $(0,0,2.5)$ \\
Düşük (D) & $(0,2.5,5)$ \\
Orta (O) & $(2.5,5,7.5)$ \\
Yüksek (Y) & $(5,7.5,10)$ \\
Çok Yüksek (ÇY) & $(7.5,10,10)$ \\
\hline
\end{tabular}

Kaynak: (Yazdani, 2011: 30; Chang vd., 2012: 7395)

Adım 2: Karar vericiler tarafindan oluşturulan karar matrisleri, $K$ karar vericilerin sayısını göstermek üzere Eşitlik (6) yardımıyla birleştirilmiş karar matrisine dönüştürülür (Fouladgar vd., 2012: 172; Ebrahimi, 2016: 346).

$$
\begin{aligned}
& x_{i j}=\left(x_{i j 1}, x_{i j 2}, x_{i j 3}\right) \\
& x_{i j 1}=\min \left\{x_{i j k 1}\right\}, \quad x_{i j 2}=\frac{1}{K} \sum_{k=1}^{K} x_{i j k 2}, \quad x_{i j 3}=\max \left\{x_{i j k 3}\right\}
\end{aligned}
$$

Adım 3: Karar vericiler tarafından oluşturulan birleştirilmiş bulanık karar matrisindeki değerler Eşitlik (7) yardımı ile durulaştırılıp kesin değerlere dönüştürülerek BNP (Best Nonfuzzy Performance Value) değerleri elde edilir (Hsieh vd., 2004: 578).

$$
B N P=\frac{(u-l)+(m-l)}{3}+l
$$

Adım 4: Eşitlik (8) yardımıyla normalize karar matrisi elde edilir.

$$
\overline{x_{i j}}=\frac{x_{i j}}{\sum_{i=1}^{m} x_{i j}} ; i=1, \ldots, m \text { ve } j=1, \ldots, n
$$

Adım 5: Eşitlik (9) yardımıyla ağırlıklı normalize karar matrisi elde edilir. 


$$
x_{i j}=\overline{x_{i j}} \cdot w_{j} ; i=1, \ldots, m \text { ve } j=1, \ldots, n
$$

Adım 6: Eşitlik (10) yardımıyla, amaca ulaşmada daha yüksek değerlerin daha iyi durumu gösterdiği faydalı kriterler için ağırlıklı normalize edilmiş karar matrisindeki değerlerin toplamı elde edilir. Daha sonra, Eşitlik (11) yardımıyla, amaca ulaşmada daha düşük değerlerin daha iyi durumu gösterdiği faydasız kriterler için ağırlıklı normalize edilmiş karar matrisindeki değerlerin toplamı hesaplanır (Aksoy vd., 2015: 13).

$$
\begin{aligned}
P_{i} & =\sum_{j=1}^{q} x_{i j} \quad j=1,2, \ldots ., q \text { faydalı kriterler } \\
R_{i} & =\sum_{j=q+1}^{n} x_{i j} \quad j=q+1, q+2, \ldots ., n \text { faydasız kriterler }
\end{aligned}
$$

Adım 7: Eşitlik (12) yardımıyla alternatiflerin göreli önem değerleri $\left(Q_{i}\right)$ hesaplanır.

$$
Q_{i}=P_{i}+\frac{\sum_{i=1}^{m} R_{i}}{R_{i} \sum_{i=1}^{m} \frac{1}{R_{i}}}
$$

Adım 8: Eşitlik (13) yardımıyla en yüksek göreli önem değeri hesaplanır.

$$
K=\max Q_{i} ; i=1, \ldots, m
$$

Adım 9: Eşitlik (14) yardımıyla alternatiflerin performans indeks değerleri $\left(N_{i}\right)$ hesaplanır.

$$
N_{i}=\frac{Q_{i}}{Q_{\max }} .100 \% ; i=1, \ldots, m
$$

\section{UYGULAMA}

Çiftçiler, meyve ve sebzelerinin bozulmalarını engellemek, ürünlerin tazeliğini korumak, ürünlerini daha elverişli fiyatlardan satmak amacıyla ürünlerini soğuk hava depolarında saklamaktadır. Bu çalışmada da, Denizli ilinin Çivril ilçesinde tarımsal faaliyetler ile uğraşan çiftçilerin, hasattan sonra meyve ve sebzelerini saklamaları için en uygun soğuk hava deposu alternatifinin seçilmesi problemi ele alınmıştır.

3 çiftçinin karar verici olarak değerlendirmede bulunduğu bu çalışmada, Çivril'de yer alan soğuk hava depoları içerisinden her türlü meyve ve sebzenin depolanabildiği 5 soğuk hava deposu alternatifi, karar vericiler tarafından belirlenen 7 kriter altında, ÇKKV yöntemlerinden SWARA ve bulanık COPRAS yöntemleri yardımıyla değerlendirilmiştir. SWARA yöntemi ile kriterlerin ağırlıkları belirlendikten sonra, bulanık COPRAS yöntemi ile en uygun soğuk hava deposu seçilmiştir.

\subsection{SWARA Yöntemi ile Kriter Ağırlıklarının Belirlenmesi}

Çalışmada kullanılacak olan değerlendirme kriterleri, Denizli ilinin Çivril ilçesinde tarımsal faaliyetler ile uğraşan ve çalışmada karar verici (KV) olarak yer alan 3 çiftçi ile bire bir 
görüşme sonrasında elde edilmiştir. Bu görüşmeler sonrasında elde edilen değerlendirme kriterleri Tablo 3’te gösterilmiştir.

\section{Tablo 3: Değerlendirme Kriterleri}

\begin{tabular}{ll}
\hline \multicolumn{1}{c}{ Kriterler } \\
\hline $\mathrm{K}_{1}$ & Maliyet \\
$\mathrm{K}_{2}$ & Ürün Kaybı \\
$\mathrm{K}_{3}$ & Depolama Kalitesi \\
$\mathrm{K}_{4}$ & Personel Sayısı \\
$\mathrm{K}_{5}$ & Yükleme ve Boşaltma Alanı \\
$\mathrm{K}_{6}$ & Teknolojik Altyapı \\
$\mathrm{K}_{7}$ & Uzaklık \\
\hline
\end{tabular}

Alternatiflerin değerlendirilmesi amacıyla belirlenen 7 kriterin ağırlıkları SWARA yöntemi ile aşağıda verilen adımlar ile belirlenmiştir.

Adım 1: Öncelikle karar vericilerden kriterleri en önemliden en önemsize doğru sıralamaları istenmiştir. Sıralama sonuçları Tablo 4’te gösterilmiştir.

Tablo 4: Kriterlerin Karar Vericiler Tarafından Önem Derecesine Göre Suralanması

\begin{tabular}{cccc}
\hline & $\mathbf{K V}_{\mathbf{1}}$ & $\mathbf{K V}_{\mathbf{2}}$ & $\mathbf{K V}_{\mathbf{3}}$ \\
\hline $\mathrm{K}_{1}$ & 2 & 3 & 1 \\
$\mathrm{~K}_{2}$ & 1 & 1 & 2 \\
$\mathrm{~K}_{3}$ & 3 & 2 & 3 \\
$\mathrm{~K}_{4}$ & 4 & 5 & 5 \\
$\mathrm{~K}_{5}$ & 5 & 4 & 4 \\
$\mathrm{~K}_{6}$ & 6 & 6 & 6 \\
$\mathrm{~K}_{7}$ & 7 & 7 & 7 \\
\hline
\end{tabular}

Karar vericiler tarafindan her bir kriterin göreli önem düzeyleri en önemli kritere 1,00 değeri verilmek şartı ile ayrı ayrı belirlenmiștir. Karar vericiler tarafından kriterlere verilen değerler Tablo 5'te gösterilmiştir.

Tablo 5: Kriterlerin Karar Vericiler Tarafindan Önem Derecesine Göre Puanlanması

\begin{tabular}{llll}
\hline & $\mathbf{K V}_{\mathbf{1}}$ & $\mathbf{K V}_{\mathbf{2}}$ & $\mathbf{K V}_{\mathbf{3}}$ \\
\hline $\mathrm{K}_{1}$ & 0.95 & 0.90 & 1.00 \\
$\mathrm{~K}_{2}$ & 1.00 & 1.00 & 0.95 \\
$\mathrm{~K}_{3}$ & 0.85 & 0.95 & 0.90 \\
$\mathrm{~K}_{4}$ & 0.70 & 0.70 & 0.70 \\
$\mathrm{~K}_{5}$ & 0.60 & 0.80 & 0.80 \\
$\mathrm{~K}_{6}$ & 0.55 & 0.65 & 0.65 \\
$\mathrm{~K}_{7}$ & 0.30 & 0.50 & 0.40 \\
\hline
\end{tabular}


Adım 2: Eşitlik (1) yardımı ile kriterlerin göreli ortalama önem puanları bulunmuş ve Tablo 6'da gösterilmiştir.

\section{Tablo 6: Kriterlerin Ortama Önem Puan Değerleri}

\begin{tabular}{cc}
\hline Kriterler & Ortalama Önem Puanları \\
\hline $\mathrm{K}_{1}$ & 0.95 \\
$\mathrm{~K}_{2}$ & 0.98 \\
$\mathrm{~K}_{3}$ & 0.90 \\
$\mathrm{~K}_{4}$ & 0.70 \\
$\mathrm{~K}_{5}$ & 0.73 \\
$\mathrm{~K}_{6}$ & 0.62 \\
$\mathrm{~K}_{7}$ & 0.40 \\
\hline
\end{tabular}

Adım 3: Tablo 6'da yer alan kriterlerin ortalama önem puan değerleri siralanarak, kriterlerin ortalama değerin karşılaştırmalı önem değerleri bulunmuş ve bu değerler Tablo 7'de gösterilmiştir.

Tablo 7: Kriterlerin Ortalama Değerinin Karşılaştırmalı Önem Değerleri

\begin{tabular}{ccc}
\hline Kriterler & $\boldsymbol{P}_{\boldsymbol{i}}$ & $\boldsymbol{S}_{\boldsymbol{j}}$ \\
\hline $\mathrm{K}_{2}$ & 0.98 & \\
$\mathrm{~K}_{1}$ & 0.95 & 0.03 \\
$\mathrm{~K}_{3}$ & 0.90 & 0.05 \\
$\mathrm{~K}_{5}$ & 0.73 & 0.17 \\
$\mathrm{~K}_{4}$ & 0.70 & 0.03 \\
$\mathrm{~K}_{6}$ & 0.62 & 0.08 \\
$\mathrm{~K}_{7}$ & 0.40 & 0.22 \\
\hline
\end{tabular}

Adım 4: Eşitlik (2) yardımı ile kriterlerin katsayı değerleri bulunmuş ve Tablo 8'de gösterilmiştir.

\section{Tablo 8: Kriterlerin Katsayı Değerleri}

\begin{tabular}{cc}
\hline Kriterler & $\boldsymbol{c}_{\boldsymbol{j}}$ \\
\hline $\mathrm{K}_{2}$ & 1.00 \\
$\mathrm{~K}_{1}$ & 1.03 \\
$\mathrm{~K}_{3}$ & 1.05 \\
$\mathrm{~K}_{5}$ & 1.17 \\
$\mathrm{~K}_{4}$ & 1.03 \\
$\mathrm{~K}_{6}$ & 1.08 \\
$\mathrm{~K}_{7}$ & 1.22 \\
\hline
\end{tabular}


Adım 5: Eşitlik 3 yardımı ile kriterlerin düzeltilmiş ağırlıkları bulunarak Tablo 9'da gösterilmiştir.

Tablo 9: Kriterlerin Düzeltilmiş Ağırlık Değerleri

\begin{tabular}{cc}
\hline Kriterler & $\boldsymbol{s}_{\boldsymbol{j}}{ }^{\prime \prime}$ \\
\hline $\mathrm{K}_{2}$ & 1.00 \\
$\mathrm{~K}_{1}$ & 0.97 \\
$\mathrm{~K}_{3}$ & 0.92 \\
$\mathrm{~K}_{5}$ & 0.79 \\
$\mathrm{~K}_{4}$ & 0.76 \\
$\mathrm{~K}_{6}$ & 0.71 \\
$\mathrm{~K}_{7}$ & 0.58 \\
\hline
\end{tabular}

Adım 6: Eşitlik (4) yardımı ile kriterlerin nihai ağırlık değerleri bulunmuş ve Tablo 10'da gösterilmiştir.

Tablo 10: Kriterlerin Nihai Ağırlık Değerleri

\begin{tabular}{cc}
\hline Kriterler & $\boldsymbol{w}_{\boldsymbol{j}}$ \\
\hline $\mathrm{K}_{2}$ & 0.175 \\
$\mathrm{~K}_{1}$ & 0.169 \\
$\mathrm{~K}_{3}$ & 0.161 \\
$\mathrm{~K}_{5}$ & 0.138 \\
$\mathrm{~K}_{4}$ & 0.133 \\
$\mathrm{~K}_{6}$ & 0.123 \\
$\mathrm{~K}_{7}$ & 0.101 \\
\hline
\end{tabular}

\subsection{Bulanık COPRAS Yöntemi ile Alternatiflerin Değerlendirilmesi}

SWARA yöntemi ile kriter ağılıklarının belirlenmesinden sonra, Bulanık COPRAS yöntemi ile alternatiflerin değerlendirilerek en iyi soğuk hava deposunun seçimi aşağıdaki adımlar ile belirlenmiştir.

Adım 1: Alternatifler Tablo 2'deki sözel değişkenler ile üç karar verici tarafindan değerlendirilmiş ve ilgili sözel değişkenlerin bulanık sayı karşılıklarından yararlanılarak her bir karar verici için bulanık karar matrisleri oluşturulmuştur. Bu karar matrisleri sırasıyla Tablo 11, Tablo 12 ve Tablo 13’te gösterilmiştir.

Tablo 11: Birinci Karar Verici Tarafindan Oluşturulan Bulanık Karar Matrisi

\begin{tabular}{cccccccc}
\hline & $\mathbf{K}_{\mathbf{1}}$ & $\mathbf{K}_{\mathbf{2}}$ & $\mathbf{K}_{\mathbf{3}}$ & $\mathbf{K}_{\mathbf{4}}$ & $\mathbf{K}_{\mathbf{5}}$ & $\mathbf{K}_{\mathbf{6}}$ & $\mathbf{K}_{\mathbf{7}}$ \\
\hline $\mathbf{A}_{\mathbf{1}}$ & $(7.5,10,10)$ & $(0,2.5,5)$ & $(5,7.5,10)$ & $(0,2.5,5)$ & $(2.5,5,7.5)$ & $(5,7.5,10)$ & $(2.5,5,7.5)$ \\
$\mathbf{A}_{\mathbf{2}}$ & $(2.5,5,7.5)$ & $(0,0,2.5)$ & $(7.5,10,10)$ & $(2.5,5,7.5)$ & $(0,2.5,5)$ & $(5,7.5,10)$ & $(2.5,5,7.5)$ \\
$\mathbf{A}_{\mathbf{3}}$ & $(5,7.5,10)$ & $(0,2.5,5)$ & $(5,7.5,10)$ & $(5,7.5,10)$ & $(5,7.5,10)$ & $(2.5,5,7.5)$ & $(0,2.5,5)$ \\
$\mathbf{A}_{\mathbf{4}}$ & $(7.5,10,10)$ & $(0,2.5,5)$ & $(5,7.5,10)$ & $(2.5,5,7.5)$ & $(5,7.5,10)$ & $(7.5,10,10)$ & $(5,7.5,10)$ \\
$\mathbf{A}_{\mathbf{5}}$ & $(5,7.5,10)$ & $(2.5,5,7.5)$ & $(2.5,5,7.5)$ & $(0,2.5,5)$ & $(5,7.5,10)$ & $(2.5,5,7.5)$ & $(0,2.5,5)$ \\
\hline
\end{tabular}


Tablo 12: İkinci Karar Verici Tarafından Olușturulan Bulanık Karar Matrisi

\begin{tabular}{cccccccc}
\hline & $\mathbf{K}_{\mathbf{1}}$ & $\mathbf{K}_{\mathbf{2}}$ & $\mathbf{K}_{\mathbf{3}}$ & $\mathbf{K}_{\mathbf{4}}$ & $\mathbf{K}_{\mathbf{5}}$ & $\mathbf{K}_{\mathbf{6}}$ & $\mathbf{K}_{\mathbf{7}}$ \\
\hline $\mathbf{A}_{\mathbf{1}}$ & $(7.5,10,10)$ & $(0,0,2.5)$ & $(7.5,10,10)$ & $(2.5,5,7.5)$ & $(5,7.5,10)$ & $(5,7.5,10)$ & $(2.5,5,7.5)$ \\
$\mathbf{A}_{\mathbf{2}}$ & $(5,7.5,10)$ & $(0,2.5,5)$ & $(5,7.5,10)$ & $(2.5,5,7.5)$ & $(5,7.5,10)$ & $(2.5,5,7.5)$ & $(2.5,5,7.5)$ \\
$\mathbf{A}_{\mathbf{3}}$ & $(5,7.5,10)$ & $(2.5,5,7.5)$ & $(2.5,5,7.5)$ & $(5,7.5,10)$ & $(5,7.5,10)$ & $(2.5,5,7.5)$ & $(2.5,5,7.5)$ \\
$\mathbf{A}_{\mathbf{4}}$ & $(5,7.5,10)$ & $(0,2.5,5)$ & $(5,7.5,10)$ & $(2.5,5,7.5)$ & $(2.5,5,7.5)$ & $(7.5,10,10)$ & $(2.5,5,7.5)$ \\
$\mathbf{A}_{\mathbf{5}}$ & $(7.5,10,10)$ & $(0,0,2.5)$ & $(5,7.5,10)$ & $(5,7.5,10)$ & $(7.5,10,10)$ & $(5,7.5,10)$ & $(2.5,5,7.5)$ \\
\hline
\end{tabular}

Tablo 13: Üçüncü Karar Verici Tarafindan Oluşturulan Bulanık Karar Matrisi

\begin{tabular}{cccccccc}
\hline & $\mathbf{K}_{\mathbf{1}}$ & $\mathbf{K}_{\mathbf{2}}$ & $\mathbf{K}_{\mathbf{3}}$ & $\mathbf{K}_{\mathbf{4}}$ & $\mathbf{K}_{\mathbf{5}}$ & $\mathbf{K}_{\mathbf{6}}$ & $\mathbf{K}_{\mathbf{7}}$ \\
\hline $\mathbf{A}_{\mathbf{1}}$ & $(7.5,10,10)$ & $(0,2.5,5)$ & $(7.5,10,10)$ & $(0,2.5,5)$ & $(2.5,5,7.5)$ & $(7.5,10,10)$ & $(5,7.5,10)$ \\
$\mathbf{A}_{\mathbf{2}}$ & $(2.5,5,7.5)$ & $(0,2.5,5)$ & $(5,7.5,10)$ & $(2.5,5,7.5)$ & $(2.5,5,7.5)$ & $(5,7.5,10)$ & $(2.5,5,7.5)$ \\
$\mathbf{A}_{\mathbf{3}}$ & $(5,7.5,10)$ & $(0,2.5,5)$ & $(5,7.5,10)$ & $(7.5,10,10)$ & $(5,7.5,10)$ & $(2.5,5,7.5)$ & $(2.5,5,7.5)$ \\
$\mathbf{A}_{\mathbf{4}}$ & $(5,7.5,10)$ & $(0,0,2.5)$ & $(5,7.5,10)$ & $(2.5,5,7.5)$ & $(5,7.5,10)$ & $(5,7.5,10)$ & $(5,7.5,10)$ \\
$\mathbf{A}_{\mathbf{5}}$ & $(5,7.5,10)$ & $(2.5,5,7.5)$ & $(2.5,5,7.5)$ & $(5,7.5,10)$ & $(7.5,10,10)$ & $(2.5,5,7.5)$ & $(0,0,2.5)$ \\
\hline
\end{tabular}

Adım 2: Karar vericiler tarafından oluşturulan karar matrisleri Eşitlik (6) yardımıyla birleştirilmiş karar matrisine dönüştürülmüş ve Tablo 14'te gösterilmiştir.

Tablo 14: Birleştirilmiş Bulanık Karar Matrisi

\begin{tabular}{cccccccc}
\hline & $\mathbf{K}_{\mathbf{1}}$ & $\mathbf{K}_{\mathbf{2}}$ & $\mathbf{K}_{\mathbf{3}}$ & $\mathbf{K}_{\mathbf{4}}$ & $\mathbf{K}_{\mathbf{5}}$ & $\mathbf{K}_{\mathbf{6}}$ & $\mathbf{K}_{\mathbf{7}}$ \\
\hline $\mathbf{A}_{\mathbf{1}}$ & $(7.5,10,10)$ & $(0,1.7,5)$ & $(5,9.2,10)$ & $(0,3.3,7.5)$ & $(2.5,5.8,10)$ & $(5,8.3,10)$ & $(2.5,5.8,10)$ \\
$\mathbf{A}_{\mathbf{2}}$ & $(2.5,5.8,10)$ & $(0,1.7,5)$ & $(5,8.3,10)$ & $(2.5,5,7.5)$ & $(0,5,10)$ & $(2.5,6.7,10)$ & $(2.5,5,7.5)$ \\
$\mathbf{A}_{\mathbf{3}}$ & $(5,7.5,10)$ & $(0,3.3,7.5)$ & $(2.5,6.7,10)$ & $(5,8.3,10)$ & $(5,7.5,10)$ & $(2.5,5,7.5)$ & $(0,4.2,7.5)$ \\
$\mathbf{A}_{\mathbf{4}}$ & $(5,8.3,10)$ & $(0,1.7,5)$ & $(5,7.5,10)$ & $(2.5,5,7.5)$ & $(2.5,6.7,10)$ & $(5,9.2,10)$ & $(2.5,6.7,10)$ \\
$\mathbf{A}_{\mathbf{5}}$ & $(5,8.3,10)$ & $(0,3.3,7.5)$ & $(2.5,5.8,10)$ & $(0,5.8,10)$ & $(5,9.2,10)$ & $(2.5,5.8,10)$ & $(0,2.5,7.5)$ \\
\hline
\end{tabular}

Adım 3: Bulanık Karar Matrisinin Durulaştırılması

Tablo 14'te yer alan birleştirilmiş bulanık karar matrisi Eşitlik (7) yardımıyla durulaştırılmış ve elde edilen sonuçlar Tablo 15 'te gösterilmiştir.

Tablo 15: Durulaştırılmış Karar Matrisi

\begin{tabular}{lccccccc}
\hline & $\mathbf{K}_{\mathbf{1}}$ & $\mathbf{K}_{\mathbf{2}}$ & $\mathbf{K}_{\mathbf{3}}$ & $\mathbf{K}_{\mathbf{4}}$ & $\mathbf{K}_{\mathbf{5}}$ & $\mathbf{K}_{\mathbf{6}}$ & $\mathbf{K}_{\mathbf{7}}$ \\
\hline $\mathbf{A}_{\mathbf{1}}$ & 9.17 & 2.22 & 8.06 & 3.61 & 6.11 & 7.78 & 6.11 \\
$\mathbf{A}_{\mathbf{2}}$ & 6.11 & 2.22 & 7.78 & 5.00 & 5.00 & 6.39 & 5.00 \\
$\mathbf{A}_{\mathbf{3}}$ & 7.50 & 3.61 & 6.39 & 7.78 & 7.50 & 5.00 & 3.89 \\
$\mathbf{A}_{\mathbf{4}}$ & 7.78 & 2.22 & 7.50 & 5.00 & 6.39 & 8.06 & 6.39 \\
$\mathbf{A}_{\mathbf{5}}$ & 7.78 & 3.61 & 6.11 & 5.28 & 8.06 & 6.11 & 3.33 \\
\hline
\end{tabular}

Adım 4: Durulaştırılan karar matrisi Eşitlik (8) yardımı ile normalize edilmiştir. Normalize karar matrisi ve Tablo 16'da gösterilmiştir. 
Tablo 16: Normalize Karar Matrisi

\begin{tabular}{cccccccc}
\hline & $\mathbf{K}_{\mathbf{1}}$ & $\mathbf{K}_{\mathbf{2}}$ & $\mathbf{K}_{\mathbf{3}}$ & $\mathbf{K}_{\mathbf{4}}$ & $\mathbf{K}_{\mathbf{5}}$ & $\mathbf{K}_{\mathbf{6}}$ & $\mathbf{K}_{\mathbf{7}}$ \\
\hline $\mathbf{A}_{\mathbf{1}}$ & 0.24 & 0.16 & 0.22 & 0.14 & 0.18 & 0.23 & 0.25 \\
$\mathbf{A}_{\mathbf{2}}$ & 0.16 & 0.16 & 0.22 & 0.19 & 0.15 & 0.19 & 0.20 \\
$\mathbf{A}_{\mathbf{3}}$ & 0.20 & 0.26 & 0.18 & 0.29 & 0.23 & 0.15 & 0.16 \\
$\mathbf{A}_{\mathbf{4}}$ & 0.20 & 0.16 & 0.21 & 0.19 & 0.19 & 0.24 & 0.26 \\
$\mathbf{A}_{\mathbf{5}}$ & 0.20 & 0.26 & 0.17 & 0.20 & 0.24 & 0.18 & 0.13 \\
\hline
\end{tabular}

Adım 5: Tablo 10'da yer alan kriterlerin ağırlık değerleri kullanılarak Eşitlik (9) yardımı ile ağırlıklandırılmış normalize karar matrisi elde edilmiş ve Tablo 17'de gösterilmiştir.

Tablo 17: Ağırlıklandırılmış Normalize Karar Matrisi

\begin{tabular}{lccccccc}
\hline & $\mathbf{K}_{\mathbf{1}}$ & $\mathbf{K}_{\mathbf{2}}$ & $\mathbf{K}_{\mathbf{3}}$ & $\mathbf{K}_{\mathbf{4}}$ & $\mathbf{K}_{\mathbf{5}}$ & $\mathbf{K}_{\mathbf{6}}$ & $\mathbf{K}_{\mathbf{7}}$ \\
\hline $\mathbf{A}_{\mathbf{1}}$ & 0.040 & 0.028 & 0.036 & 0.018 & 0.026 & 0.029 & 0.025 \\
$\mathbf{A}_{\mathbf{2}}$ & 0.027 & 0.028 & 0.035 & 0.025 & 0.021 & 0.024 & 0.020 \\
$\mathbf{A}_{\mathbf{3}}$ & 0.033 & 0.046 & 0.029 & 0.039 & 0.031 & 0.018 & 0.016 \\
$\mathbf{A}_{\mathbf{4}}$ & 0.034 & 0.028 & 0.034 & 0.025 & 0.027 & 0.030 & 0.026 \\
$\mathbf{A}_{\mathbf{5}}$ & 0.034 & 0.046 & 0.027 & 0.026 & 0.034 & 0.023 & 0.014 \\
\hline
\end{tabular}

Adım 6: Eşitlik (10) yardımı ile $P_{i}$ değerleri, Eşitlik (11) yardımı ile $R_{i}$ değerleri hesaplanmış ve Tablo 18' de verilmiştir.

Tablo 18: $P_{i}$ ve $R_{i}$ Değerleri

\begin{tabular}{ccc}
\hline Alternatifler & $\boldsymbol{P}_{\boldsymbol{i}}$ & $\boldsymbol{R}_{\boldsymbol{i}}$ \\
\hline $\mathbf{A}_{\mathbf{1}}$ & 0.108 & 0.093 \\
$\mathbf{A}_{\mathbf{2}}$ & 0.104 & 0.075 \\
$\mathbf{A}_{\mathbf{3}}$ & 0.117 & 0.094 \\
$\mathbf{A}_{\mathbf{4}}$ & 0.115 & 0.088 \\
$\mathbf{A}_{\mathbf{5}}$ & 0.110 & 0.093 \\
\hline
\end{tabular}

Adım 7: Eşitlik (12) yardımı ile alternatiflerin göreli önem değerleri hesaplanmış ve Tablo 19’ da gösterilmiştir.

Tablo 19: Alternatiflerin Göreli Önem Değerleri

\begin{tabular}{cc}
\hline Alternatifler & $\boldsymbol{Q}_{\boldsymbol{i}}$ \\
\hline $\mathbf{A}_{\mathbf{1}}$ & 2.230 \\
$\mathbf{A}_{\mathbf{2}}$ & 2.733 \\
$\mathbf{A}_{\mathbf{3}}$ & 2.215 \\
$\mathbf{A}_{\mathbf{4}}$ & 2.356 \\
$\mathbf{A}_{\mathbf{5}}$ & 2.231 \\
\hline
\end{tabular}


Adım 8: Eşitlik (13) yardımı ile en yüksek göreli önem değeri $\left(Q_{\max }\right)$ hesaplanmış ve en yüksek göreli öneme sahip olan alternatif 2,733 değeri ile $\mathrm{A}_{2}$ alternatifi olarak bulunmuştur.

Adım 9: En iyi alternatifin performans indeksi 100 değerini göstermek üzere alternatiflerin performans indeks değerleri Eşitlik (14) kullanılarak hesaplanmış ve elde edilen değerler Tablo 20'de gösterilmiştir.

Tablo 20: Alternatiflerin Performans İndeks Değerleri

\begin{tabular}{cc}
\hline Alternatifler & $\boldsymbol{Q}_{\boldsymbol{i}}$ \\
\hline $\mathbf{A}_{\mathbf{1}}$ & 81.60 \\
$\mathbf{A}_{\mathbf{2}}$ & 100 \\
$\mathbf{A}_{\mathbf{3}}$ & 81.06 \\
$\mathbf{A}_{\mathbf{4}}$ & 86.22 \\
$\mathbf{A}_{\mathbf{5}}$ & 81.65 \\
\hline
\end{tabular}

Tablo 20'de Bulanık COPRAS yöntemi ile hesaplama sonucunda alternatiflerin tercih sıralamaları görülmektedir. Bulanık COPRAS yöntemi sonucunda alternatifler; $A_{2}>A_{4}>A_{5}>$ $\mathrm{A}_{1}>\mathrm{A}_{3}$ şeklinde sıralanmaktadır.

\section{SONUÇ VE ÖNERILLER}

Meyve ve sebze üretimi, hem tarımsal faaliyetler ile yaşamlarını idame ettiren insanlar açısından hem de ülkenin ekonomisi açısından oldukça önemlidir. Ayrıca üretildikten sonra hasat edilen meyve ve sebzelerin tüketilinceye kadar saklanması da önemlidir. Hasat edildikten sonra tüketilmeyen ya da satılamayan ürünlerin, çürüme ya da bozulmalarına karşı sağlıklı bir şekilde depolanabilmesi gerekmektedir (Akdemir, 2002: 1). Meyve ve sebzelerin sağlıklı bir şekilde depolanabilmesi için de seçimi yapılacak olan soğuk hava deposu son derece önemlidir.

Çiftçilerin belirli bir dönemde yoğunlaşan meyve ve sebze hasatı boyunca, ürünlerinin çabuk bozulmasını engellemek ve ürünlerin tazeliğini koruyarak her mevsim tüketilmesini sağlamak amaciyla uygun soğuk hava deposunun seçilmesi önemlidir. Bu çalışma ile birlikte, çiftçilerin soğuk hava deposu alternatifleri arasından seçim yapma sürecini kolaylaştırmasına katkı sağlamak amaçlanmıştır.

Soğuk hava deposu seçim probleminin değerlendirildiği bu çalışmada SWARA ve bulanık COPRAS yöntemleri kullanılmıştır. Çalışmada kullanılan veriler Denizli ilinin Çivril ilçesinde geçimini meyve ve sebze tarımı ile sağlayan çiftçiler ile bire bir görüşmeler ile elde edilmiştir. SWARA yöntemi ile kriter ağırlıkları hesaplandıktan sonra, soğuk hava deposu alternatifleri Bulanık COPRAS yöntemi yardımıyla değerlendirilmiş ve en iyi alternatif $A_{2}$ olarak bulunmuştur. Çalışmanın sonuçlarına göre çiftçilere meyve ve sebzelerini çürüme ya da bozulmalarına karşı koruyabilmeleri için soğuk hava depolardan $\mathrm{A}_{2}$ alternatifini seçmeleri önerisinde bulunulmuştur. SWARA ve bulanık COPRAS yöntemlerinin bir arada kullanılması ve soğuk hava deposu seçimi gibi farklı bir alana uygulanarak çiftçilere yol göstermeyi amaçlaması çalışmanın literatürdeki diğer çalışmalardan farkını göstermektedir.

$\mathrm{Bu}$ çalışmada soğuk hava deposu alternatifleri ÇKKV yöntemlerinden SWARA ve bulanık COPRAS yöntemleri ile değerlendirilmiştir. Yapılan bu çalışmaya, karar vericiler tarafından belirlenen kriterlere ilave olarak başka kriterler eklenebilir, kriterlerin ağırlıkları için başka çok kriterli karar verme tekniklerinden yararlanılabilir. Ayrıca alternatiflerin 
değerlendirilmesinde, diğer ÇKKV yöntemleri ile çözüm aranabilir ve elde edilen sonuçlar karşılaştırılarak sonuçların değerlendirilmesine olanak sağlanabilir.

\section{KAYNAKÇA}

Adalı, E. A. ve Tuş Işık, A. (2017). Bir tedarikçi seçim problemi için SWARA ve WASPAS yöntemlerine dayanan karar verme yaklaşımı. International Review of Economics and Management, 5(4), 56-77.

Akdemir, S. (2002). Soğuk hava depolarında farklı soğutucu gazların soğutma etkinliğinin saptaması ve soğuk depolanan vazı tarımsal ürünler üzerindeki etkilerinin karşılaştırılması üzerinde bir araştırma, Tarakya Üniversitesi Fen Bilimleri Enstitüsü (Basılmamış Doktora Tezi), Tekirdağ.

Aksoy, E., Ömürbek, N. ve Karaatlı, M. (2015). AHP temelli MULTIMOORA ve COPRAS yöntemi ile Türkiye Kömür İşletmeleri'nin performans değerlendirmesi. Hacettepe Üniversitesi İktisadi ve İdari Bilimler Fakültesi Dergisi, 33(4), 1-28.

Baykal N. ve Beyan T. (2004), Bulanık mantık ilke ve temelleri. Ankara: Bıçaklar Kitabevi.

Chang, Y. F., Watada, J., \& Ishii, H. (2012). A fuzzy MCDM approach to building a model of high performance project team-a case study. International Journal of Innovative Computing, Information \& Control, 8, 7393-7404.

Chatterjee, N., \& Bose, G. (2013a). A COPRAS-F base multi-criteria group decision making approach for site selection of wind farm. Decision Science Letters, 2(1), 1-10.

Chatterjee, N., \& Bose, G. (2013b). Selection of vendors for wind farm under fuzzy MCDM environment. International Journal of Industrial Engineering Computations, 4(4), 535-546.

Chen, G., \& Pham, T. T. (2001). Introduction to fuzzy sets, fuzzy logic, and fuzzy control systems, Florida: CRC Press.

Kahraman, C., Cebeci, U., \& Ruan, D. (2004). Multi-attribute comparison of catering service companies using fuzzy AHP: the case of Turkey. International Journal of Production Economics, 87, 171-184.

Çakır, E. (2017). Kentsel dönüşüm kapsamında müteahhit firmanın SWARA-Gri ilişkisel analiz yöntemiyle seçilmesi. Uluslararası Bilimsel Araştırmalar Dergisi, 2(6), 79-95.

Çakır, E. ve Akar, G. S. (2016). Bütünleşik SWARA-TOPSIS yöntemi ile makine seçimi: bir üretim işletmesinde uygulama. International Journal of Academic Value Studies, 3(13), 206-216.

Çakır, E. ve Özdemir, M. (2016). Bulanık çok kriterli karar verme yöntemlerinin altı sigma projeleri seçiminde uygulanmas1. Business and Economics Research Journal, 7(2), 167-202.

Çullu, B. (2017). Tarım ürünleri lojistiği kapsamında sebze - meyve soğuk hava depolarının kuruluş yeri seçimi: Aydın ili uygulaması, Yüksek Lisans Tezi, İzmir: Dokuz Eylül Üniversitesi Sosyal Bilimler Enstitüsü.

Dahooie, H. J., Abadi, E., Vanaki B. J., Vanaki, A. S., \& Firoozfar, H. R. (2018). Competency-based IT personnel selection using a hybrid SWARA and ARAS-G methodology. Human Factors and Ergonomics in Manufacturing \& Service Industries, 28(1), 5-16.

Ebrahimi, E., Fathi, M. R., \& Irani, H. R. (2016). A new hybrid method based on fuzzy Shannon's entropy and fuzzy COPRAS for CRM performance evaluation (Case: Mellat Bank). Iranian Journal of Management Studies, 9(2), 333358.

Fouladgar, M. M., Yazdani-Chamzini, A., Zavadskas, E. K., \& Haji Moini, S. H. (2012). A new hybrid model for evaluating the working strategies: case study of construction company. Technological and Economic Development of Economy, 18(1), 164-188.

Gençoğlan, S, Özdemir, T. ve Gençoğlan, C. (2016). Kahramanmaraş ilindeki soğuk hava depolarının mevcut durumunun belirlenmesi. VII. Bahçe Ürünlerinde Muhafaza ve Pazarlama Sempozyumu, 1, 67-74.

Hatefi, S. M. (2018). Strategic planning of urban transportation system based on sustainable development dimensions using an integrated SWOT and fuzzy COPRAS approach. Global Journal of Environmental Science and Management, 4(1), 99-112.

Hsieh, T.Y., Lu, S.T. \& Tzeng, G.H. (2004). Fuzzy MCDA approach for planning and design tenders selection in public office buildings. International Journal of Project Management, 22(7), 573-584. 
Karaatl1, M., Ömürbek, N., Aksoy, E. ve Atasoy, M. (2015). Çok kriterli karar verme teknikleri ile performans değerlendirmesine ilişkin bir uygulama. Sosyal Bilimler Araştırma Dergisi, 4(2), 176-186.

Karabašević, D., Stanujkić, D., \& Urošević, S. (2015). The MCDM model for personnel selection based on SWARA and ARAS methods. Management, 77, 43-52.

Karabašević, D., Stanujkić, D., Urošević, S., \& Maksimović, M. (2016a). An approach to personnel selection based on SWARA and WASPAS methods. Journal of Economics, Management and Informatics, 7(1), 1-11.

Karabašević, D., Paunkovic, J., \& Stanujkic, D. (2016b). Ranking of companies according to the indicators of corporate social responsibility based on SWARA and ARAS methods. Serbian Journal of Managament, 11(1), 43-53.

Keršuliene V., Zavadskas, E. K., \& Turskis, Z. (2010). Selection of rational dispute resolution method by applying new step-wise weight assessment ratio analysis (SWARA). Journal of Business Economics and Management, 11(2), 243-258.

Khorasani, S. T. (2018). Green supplier evaluation by using the integrated fuzzy AHP model and fuzzy COPRAS. Process Integration and Optimization for Sustainability, 2(1), 17-25.

Nakhaei, J., Lale Arefi, S., Bitarafan, M., \& Kildienè, S. (2016). Evaluation of light supply in the public underground safe spaces by using of COPRAS-SWARA methods. International Journal of Strategic Property Management, 20(2), 198-206.

Nguyen, H. T., Dawal, S. Z. M., Nukman, Y., Aoyama, H. \& Case, K. (2015). An integrated approach of fuzzy linguistic preference based AHP and fuzzy COPRAS for machine tool evaluation", Plos one, 10(9), 1-24.

Nizamoğlu, N. M. ve Gökmen, S. (2017). "Karaman İlindeki Soğuk Depoların Mevcut Durumu, Sorunları ve Çözüm Önerileri”, Derim, 34(1), 43-50.

Nourianfar, K. ve Montazer, G. A. (2013). “A Fuzzy MCDM Approach Based on COPRAS Method to Solve Supplier Selection Problems", In Information And Knowledge Technology (IKT), 2013 5th Conference On, IEEE, 231-235.

Özbek, A. ve Demirkol, İ. (2018). "Lojistik Sektöründe Faaliyet Gösteren İşletmelerin Swara ve Gia Yöntemleri ile Analizi”, Kırıkkale Üniversitesi Sosyal Bilimler Dergisi, 8(1), 71-86.

Özkan M. (2003). Bulanık Hedef Programlama, Ekin Kitabevi, Bursa.

Ruzgys, A., Volvačiovas, R., Ignatavičius, Č. ve Turskis, Z. (2014). "Integrated Evaluation of External Wall İnsulation In Residential Buildings Using SWARA-TODIM MCDM Method”, Journal of Civil Engineering and Management, 20(1), 103-110

Sargın, S. ve Okudum, R. (2014). "Isparta İlinde Soğuk Hava Depolarının Kuruluşu, Gelişimi ve Gelişimine Etki Eden Faktörler”, SDÜ Fen Edebiyat Fakültesi Sosyal Bilimler Dergisi, 31, 111-132.

Shukla, S., Mishra, P. K., Jain, R. ve Yadav, H. C. (2016). “An Integrated Decision Making Approach For ERP System Selection Using SWARA and PROMETHEE Method”, International Journal Of Intelligent Enterprise, 3(2), 120-147.

Stanujkic, D., Djordjevic, B. ve Karabasevic, D. (2015a). "Selection of Candidates in the Process of Recruitment and Selection of Personnel Based on the SWARA and ARAS Methods", Quaestus Multidisciplinary Research Journal, 7, 53-64.

Stanujkic, D., Karabasevic, D. ve Zavadskas, E. K. (2015b). "A Framework for the Selection of A Packaging Design Based on the SWARA Method", Inzinerine Ekonomika-Engineering Economics, 26(2), 181-187.

Timur, N. (1985). Tarımsal Ürünlerin Pazarlanmasında Soğuk Depo İşletmelerinin Rolü ve Marmara Bölgesi’nde Uygulama, Anadolu Üniversitesi Basımevi, Eskişehir.

Toklu, M. C., Çağıl, G., Pazar, E. ve Faydalı, R. (2018). "SWARA-WASPAS Metodolojisine Dayalı Tedarikçi Seçimi: Türkiye'de Demir-Çelik Endüstrisi Örneği”, Akademik Platform Mühendislik Ve Fen Bilimleri Dergisi, 6(3), 113-120.

Turanoglu Bekar, E., Cakmakci, M. ve Kahraman, C. (2016). "Fuzzy COPRAS Method for Performance Measurement in Total Productive Maintenance: A Comparative Analysis", Journal of Business Economics and Management, 17(5), 663-684.

Tuş Işık, A., \& Adalı, E. A. (2016). A new integrated decision making approach based on SWARA and OCRA methods for the hotel selection problem. International Journal of Advanced Operations Management, 8(2), 140-151.

Urosevic, S., Karabasevic, D., Stanujkic, D. \& Maksimovic, M. (2017). An approach to personnel selection in the tourism industry based on the SWARA and the WASPAS methods. Economic Computation \& Economic Cybernetics Studies \& Research, 51(1), 75-88. 
Valipour, A., Yahaya, N., Md Noor, N., Antuchevičienė, J., \& Tamošaitienė, J. (2017). Hybrid SWARA-COPRAS method for risk assessment in deep foundation excavation project: an Iranian case study. Journal of Civil Engineering and Management, 23(4), 524-532.

Yazdani, M., Alidoosti, A., \& Zavadskas, E. K. (2011). Risk analysis of critical infrastructures using fuzzy COPRAS. Economic Research-Ekonomska İstraživanja, 24(4), 27-40.

Yazdani, M., Zavadaskas, E. K., Ignatius, J., \& Abad, M. D. (2016). Sensitivity analysis in MADM methods: applications of material selection. Engineering Economics, 27(4), 382-391.

Yurdoğlu, H. ve Kundakcı, N. (2017). SWARA ve WASPAS yöntemleri ile sunucu seçimi. Balıkesir Üniversitesi Sosyal Bilimler Enstitüsü Dergisi, 20(38), 253-269.

Zadeh L.A. (1965). Fuzzy sets. Information and Control, 8, 338-353.

Zadeh, L. A. (1975). The concept of a linguistic variable and its application to approximate reasoning-I, Information Sciences, 8, 199-249.

Zarbakhshnia, N., Soleimani, H., \& Ghaderi, H. (2018). Sustainable third-party reverse logistics provider evaluation and selection using fuzzy SWARA and developed fuzzy COPRAS in the presence of risk criteria. Applied Soft Computing, 65, 307-319.

Zavadskas, E. K., \& Kaklauskas, A. 1996. Systemotechnical evaluation of buildings (Pastatų sistemotechninis ìvertinimas). Vilnius: Technika, 280 p. (in Lithuanian).

Zavadskas, E. K., \& Antucheviciene, J. (2007). Multiple criteria evaluation of rural building's regeneration alternatives. Building and Environment, 42(1), 436-451.

Zolfani, S. H., \& Saparauskas, J. (2013). New application of SWARA method in prioritizing sustainability assessment indicators of energy system. Engineering Economics, 24(5), 408-414.

Zolfani, S. H., Zavadskas, E. K. \& Turskis, Z. (2013a). Desing of products with both international and local perspectives based on yin-yang balance theory and SWARA method. Economic Research, 26(2), 153-166.

Zolfani, S. H., Aghdaie, M. H., Derakhti, A. Zavadskas, E. K., \& Varzandeh, M. H. M. (2013b). Decision making on business issue with foresight perspective; an application of new hybrid MCDM model in shopping mall locating. Expert Systrms with Applications, 40(17), 7111-7121.

Zolfani, S. H., \& Bahrami, M. (2014). Investment prioritizing in high tech industries based on SWARA-COPRAS approach. Technological and Economic Development of Economy, 20(3), 534-553.

Zolfani, S. H., \& Banihashemi, S. S. A. (2014). Personnel selection based on a novel model of game theory and MCDM approaches. In Proc. of 8th International Scientific Conference Business and Management, 191-198. 


\section{Extended Summary}

\section{Selection of Cold Storage by SWARA Based Fuzzy COPRAS Method}

In this study, it was aimed to select the most suitable cold storage in Çivril district of Denizli province for vegetables and fruits in order to prevent the loss of vitamins and minerals in their structures until the products are delivered to consumers after the harvest. Cold storage alternatives where all kinds of fruits and vegetables can be stored were evaluated by using an integrated method based on SWARA (Step-Wise Weight Assessment Ratio Analysis) and Fuzzy COPRAS (Fuzzy COmplex PRoportional ASsesment) methods. For determining the weights of the criteria, SWARA method was adopted. Different methods such as AHP, MACBETH and Entropy can be used in the literature to determine the weights of the criteria. The reason why SWARA method was chosen in this study is that it provides easier calculation and it is a newer method. In addition, the SWARA method allows decision makers to set their own priorities and does not require complex pairwise comparisons like AHP and MACBETH methods, so it does not allow inconsistency. After determining the weights of the criteria with the help of SWARA method, Fuzzy COPRAS method was used in the evaluation of cold storage alternatives. Fuzzy MCDM method was preferred because the problem had many uncertainties and decision makers had difficulty in evaluating alternatives with definite expressions. So, decision makers evaluated alternatives by using linguistic variables. In addition, different fuzzy MCDM methods such as Fuzzy TOPSIS, Fuzzy ELECTRE, Fuzzy MOORA can be used to evaluate the alternatives. In this study, the reason for choosing Fuzzy COPRAS method is that the number of studies performed in this field is not too much and the method does not contain complex calculations even if the number of criteria and alternatives are high. Another important feature of the Fuzzy COPRAS method is that the values of the alternatives can be expressed as a percentage thanks to the calculated performance index, which makes it easier to make comparisons between alternatives. The unique aspect of this study is the use of SWARA and Fuzzy COPRAS methods together and their application to a different area such as cold storage selection. These two aspects contribute to the literature. In addition to this, farmers were guided in the selection of the most suitable cold storage which prevented the spoilage of fruit and vegetables and could be consumed in all seasons.

In the evaluation of cold storage alternatives with the integrated method based on SWARA and Fuzzy COPRAS methods, firstly 7 evaluation criteria were determined after faceto-face interviews with 3 farmers as decision makers to evaluate 5 cold storage alternatives. These criteria were determined as; Cost (K1), Product Loss (K2), Storage Quality (K3), Number of Personnel (K4), Loading and Unloading Area (K5), Technological Infrastructure (K6), and Distance (K7). Then, weights of criteria were determined with SWARA method, which is widely used in determining criterion weights. As a result of the SWARA method, criteria weights were obtained as;

K1 Cost: 0.169

K2 Product Loss: 0.175

K3 Storage Quality: 0.161

K4 Number of Personnel: 0.133

K5 Loading and Unloading Area: 0.138

K6 Technological Infrastructure: 0.123

K7 Distance: 0.101.

According to these obtained values, product loss criterion has the highest weight and distance criterion has the lowest weight.

After the determination of criteria weights by SWARA method, Fuzzy COPRAS method was used to evaluate 5 cold storage alternatives. In Fuzzy COPRAS method, firstly decision makers evaluated the cold storage alternatives by using linguistic variables (Very Low, Low, Medium, High, and Very High). Later, fuzzy decision matrices were formed for each decision 
maker by using triangular fuzzy number equivalents of related linguistic variables. Then, fuzzy decision matrix was constructed by integrating the evaluation results of the three decision makers. The values in this fuzzy decision matrix were defuzzified and then the obtained decision matrix was normalized. The values on the normalized matrix were multiplied with the criteria weights obtained by SWARA method in order to obtain weighted normalized decision matrix. The sum of the values in the weighted normalized decision matrix were calculated for both benefit and cost criteria. Finally, relative importance values and performance index values of alternatives were obtained. Then alternatives were ranked in descending order of their performance index values. As a result of evaluation with Fuzzy COPRAS method, ranking of the cold storage alternatives were determined as A2> A4> A5> A1> A3. According to the results of the study, farmers were advised to choose A2 alternative from cold storage alternatives in order to protect their fruits and vegetables against decay or spoilage.

The difference of this study from other studies in the literature is using the SWARA and Fuzzy COPRAS methods together and applying them to a different area such as cold storage selection by aiming to guide farmers.

In this study, cold storage alternatives were evaluated with a method based on the integration of SWARA and Fuzzy COPRAS methods. In addition to the criteria determined by the decision makers, different criteria can be added and other multi-criteria decision making methods can be used for determining the weights of the criteria. Furthermore, in the evaluation of alternatives, other fuzzy MCDM methods can be used and the results can be compared. 